Cuad. invest. hist. Brocar n. 16 (1990). Págs. 51-60.

\title{
EL CASTILLO DE CLAVIJO
}

\author{
Julián Ruiz-Navarro Pérez
}

\begin{abstract}
RESUMEN.- Se estudia el castillo roquero de Clavijo, situado en el interfluvio de los rios Iregua y Leza, en el punto de contacto entre la Sierra y el Valle. Tiene una posición privilegiada por su amplio campo visual y por su dificil accesibilidad. Del análisis de su tipología y sistema constructivo se llega a la conclusión de que es una fortaleza de origen musulman y, por tanto, datable no más tarde del año 923.

Las funciones que desempeño a lo largo de la historia fueron varias: en su origen defendio el valle de los montañeses cameranos y sirvio de refugio frente a los pamploneses; y una vez en manos castellanas, formó parte de la línea defensiva contra el reino de Navarra por su posición fronteriza.

SUMMARY.- The rocky castle of Clavijo, between the rivers Iregua and Leza is situated at the junction of the sierra and the valley. It has and exceptionally good position because of its wide field of vison and its difficult accesibility. Analysing its typology and system of building you come to the conclusion that its is a fortress with a mosiem origin and therefore it does not date back later than the year 923 .

The functions that it performed throughout history were various: in its origin it defended de Valley of the Cameros highlanders and served as a refuger against the people of Pamplona and when it belonged to Castilla, it became part of the defensive line against the kingdom of Navarra because of its border position.
\end{abstract}

\footnotetext{
Palabras clave: Clavijo, Castillo, Fortaleza, Musulmán, Fernán González, Alfonso VI, Monasterio San Martín de Albelda, Reino Pamplona-Nájera.
}

\section{SITUACIÓN GEOGRÁFICA}

Se encuentra en la localidad de Clavijo a $17 \mathrm{Kms}$ al Sur de la ciudad de Logroño. Las coordenadas geográficas son las siguientes: $42^{\circ}$ latitud Norte y $1 \stackrel{0}{15}, 30$ longitud Este, según las cartas geográficas del Servicio Geográfico del Ejército, EI:50.000, del año 1952, hoja de Logroño 23-10 (204). 


\section{EMPLAZAMIENTO TOPOGRÁFICO Y ENLACES ÓPTICOS}

El castillo se asienta sobre una imponente roca de conglomerado que tiene forma oblonga y cima irregular. A sus pies y en su vertiente oriental, única accesible, está la villa de Clavijo a una altitud aproximada de 850 metros.

La fortaleza es una espléndida atalaya desde la que se divisa un amplio panorama que comprende los valle bajos de los ríos Leza e Iregua, la comarca de Logroño, la Sonsierra desde el Toloño hasta la Peña de Codés, la Solana navarra y en días claros los Pirineos navarro-aragoneses. Por el sur el campo visual es más reducido, porque Clavijo está adosado al último eslabón de la Sierra de Camero Viejo.

\section{DESCRIPCIÓN ARQUITECTÓNICA}

La planta del castillo se compone de dos elementos básicos: un recinto central configurado por la torre del homenaje rectangular, un pequeño patio y un reducido habitáculo que ocupan la parte más elevada de la roca; y una cortina de murallas reforzada con torrecillas cilíndricas que cierra y defiende la parte superior de la misma por el lado oriental accesible. La puerta de ingreso está situada en la zona más baja de la fortaleza.

El estado ruinoso del recinto central hace díficil una reconstrucción mental del mismo, sobre todo el lado meridional cuyo muro ha desaparecido completamente.

Tampoco es fácil hacerse idea de como estaban comunicados los diferentes ámbitos del castillo.

Todo el conjunto está construido con tapial encofrado compuesto de piedra y tierra con un alto porcentaje de yeso, motivo por el cual da la sensación que los muros están enlucidos. En el torreón hay vestigios del empleo de entramados de madera para reforzar el tapial. También se observa en el ángulo Suroriental de la torre aparejo de sillería perteneciente a una reconstrucción posterior.

La torre del homenaje estaba dividida en tres pisos o plantas con vigas de madera cuyos mechinales son todavía visibles. El acceso a los pisos debió hacerse mediante escaleras de mano, aunque la existencia de un hueco en media caña que recorre el muro meridional de arriba a abajo, podría hacer pensar en una escalera fija en husillo. El desmochamiento de la parte superior tampoco nos permite saber, si se remataba con almenas, al igual que la muralla, o si tenía tejado y cadalsos.

Detrás de la torre hay un patio y un habitáculo cubierto que tiene los muros semiderruídos, pero con vestigios de contrafuertes cilíndricos en los ángulos.

La muralla de I,30 mts. de espesor tiene adarve y almenas en capirote. Se refuerza con torrecillas cilíndricas macizas hasta la altura del adarve y huecas y almenadas en la parte superior. Había espacio suficiente para que pudieran maniobrar uno o dos defesnores. Su distribución es la siguiente: dos de mayor diámetro en los extremos y otras tres irregularmente repartidas en el lienzo de muralla situado a la izquierda de la puerta de ingreso.

1 Dirigió las obras de restauración D. Antonio Fernández Ruiz-Navarro. 
Esta puerta presenta un arco de herradura califal después de la restauración efectuada por el arquitecto de la Diputación de la Rioja en 1970'. Desconocemos si la original era así, pues antes de la restauración no había restos de dovelaje.

Una vez franqueada la puerta encontramos un murete que protege un estrecho paso del abismo. Para alcanzar el recinto central había que salvar primero un muro que arranca de la muralla y se encarama sobre la roca. Desconocemos la forma de salvar dicho muro.

La carencia de datos documentales hace problemática la datación de este castillo que suponemos de origen musulmán basándonos en las técnicas empleadas en su construcción y en su tipología, que concuerdan con dos modelos de fortaleza musulmana descritos por Levy-Provenzal y Torres Balbás.

Levy-Provenzal ${ }^{2}$ nos habla de un tipo de fortificación denominada "hins" que estaban emplazados en lugares elevados, sobre rocas inaccesibles. Tenían un sólido cinturón de murallas, salvo el caso que la roca estuviera cortada a pico por alguno de sus lados. La muralla era de mamposteria o tapial y estaba flanqueada por torres y fortines en los ángulos y poseían adarve y almenas. Estas pequeñas fortificaciones solamente servían de refugio en caso de un ataque enemigo, por lo que contaban con unas pocas instalaciones permanentes como aljibes, almacenes y alojamientos elementales para la tropa. Fuera del recinto murado estaba el poblado, donde vivía la guarnición que en caso de alerta se refugiaba en la fortaleza.

Torres Balbás ${ }^{3}$ describe otrotipo de fortificación denominada alcocer que se reducía a una torre de 7,50 x 5,50 mts. con varios pisos holladeros de madera y un cinturón de murallas.

Esta teoría del origen musulmán del castillo de Clavijo se refuerza con la noticia de la captura del conde de Castilla Fernán González por el rey de Pamplona García Sánchez en Cirueña y su confinamiento en Pamplona, Clavijo y Tobía. Ocurrían estos hechos el año $960^{4}$, unos años después de la conquista de la Rioja Alta, Nájera y Viguera por Sancho Garcés I de Pamplona y Ordoño II de León, por lo que no creemos que lo construyeran los navarros.

El castillo de Clavijo sirvió de refugio seguro para la guarnición y para los campesinos de la zona frente a los ataques de los pamploneses y leoneses que desde los primeros años del siglo $\mathrm{X}$ eran frecuentes y peligrosos. Pudo utilizarse también como torre de señales por su estratégica situación y su amplio campo visual.

Otra hipótesis ${ }^{5}$ muy sugestiva considera las fortalezas de Clavijo, Viguera, Nájera, Ocón, Enciso, Arnedo, Cervera del río Alhama y posiblemente Ojacastro y Jubera los eslabones de una cadena defensiva creada por los musulmanes para proteger las ricas tierras del valle del Ebro y sus afluentes de las depredaciones de los montañeses no sometidos al Islam. Es sabido el desprecio de los musulmanes por las tierras frías y pobres de las montañas del Norte y este desprecio puede hacerse extensivo a la Sierra de Cameros, donde se cobijaron los hispanovisigodos que huyeron de los invasores. Se

2 Levy-Provenzal en "La España musulmana", Historia de España, dirigida por Menéndez Pidal, pp 235-237.

3 Torres Balbás: en la "España musulmana", Historia de España, dirigida por Menéndez Pidal, p. 628.

4 Goicoechea, C.: Los castillos... p. 1949, p.42.

5 Esta teoría de los Cameros libres del dominio musulmán la defiende Jesús de Leza. 
abrió así un nuevo capítulo de la eterna lucha entre el pastor montañés y el agricultor del valle. Estas fortalezas están situadas en el punto de contacto del valle con la montaña, por consiguiente taponaban los accesos o caminos que comunicaban las dos partes.

Clavijo protegía el paso del río Leza, pues el primitivo camino iba por Clavijo y Trevijano hasta Soto, salvando de esta manera el peligroso e intransitable cañón de dicho río.

Una vez en manos de los cristianos continuó utilizándose y son frecuentes las citas documentales que aluden a Clavijo, tanto en la época en la que esta región perteneció al reino de Pamplona y Nájera, como cuando la Rioja fue incorporada por Alfonso VI al reino de Castilla.

\section{DATOS HISTORICOS}

Las primeras noticias que poseemos datan del siglo $\mathrm{X}$, como ya hemos indicado anteriormente.

En el año 960 el conde de Castilla Fernán González fue hecho prisionero por García Sánchez de Pamplona en Cirueña y llevado primero a Pamplona y después al castillo de Clavijo, de donde lo trasladó al de Tobía.

En el catálogo del abad Mirón de Albelda figura la donación del castillo de Clavijo al monasterio de San Martín de Albelda por el rey Sancho III el Mayor de Pamplona el año $1033^{6}$.

En la escritura de donación del patronato de Santa Coloma, hecha por el rey García el de Nájera y su esposa Doña Estefanía en 1046, aparece un Eneco López señor de Clavijo. Otro alcaide de la fortaleza de Clavijo en 1048 era Fortunio López de Ulli. En otra escritura del Becerro de Valvanera del año 1078 aparece Fortunio Iohannes como señor de Clavijo?.

En 1177 era reclamado con otras fortalezas por el rey de Navarra Sancho VI el Sabio a Alfonso VIII de Castilla en virtud de un compromiso del año anterior ${ }^{8}$.

En 1285 Sancho IV y su esposa Dña. María confirmaban un privilegio que él mismo había concedido, siendo infante, concediendo el castillo de Clavijo con la mampuesta y la villa al Concejo de Logroño, en premio a sus servicios a la corona, porque habían cobrado dicho castillo a D. Juan Alfonso de Haro?.

En 1311 el rey Fernando IV concedía al cabildo de los canónigos de San Martín de Albelda los lugares de Palazuelos y Bueyo con todos sus derechos, "salvo los que se siguen que son para la tenencia de nuestro castillo de Clavijo"10.

En 1396 Diego López de Zúñiga, Justicia mayor del rey de Castilla dió a su hijo Iñigo casado con Juana, hija bastarda del rey de Navarra Carlos III el Noble, cuatro

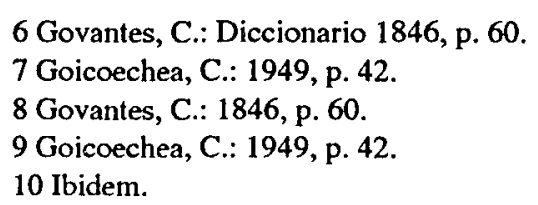


aldeas en el obispado de Calahorra, Clavijo, Baños, Huércanos y Bobadilla, como regalo de bodas ${ }^{11}$.

En 1440 Juan II de Castilla concedió las tenencias de las fortalezas de Alfaro y Clavijo a Juan de Luna, hijo de Juan Hurtado de Mendoza, que fué merino mayor del reino, y sobrino de D. Alvaro de Luna, Condestable de Castilla ${ }^{12}$.

En 1476D. Pedro López de Zúñiga, hijo mayor de D. Diego López de Zúñiga vendió la aldea y castillo de Clavijo, con otros lugares a los condes de Aguilar, Señores de Cameros por 400.000 maravedies $^{13}$.

Este breve repertorio documental referido al castillo de Clavijo pone de manifiesto la versátil y cambiante situación política que vivió esta región durante la Edad Media y la relativa facilidad con que cambia de dueño.

Después de la conquista de Viguera y Nájera por los pamploneses y leoneses debió perder su operatividad original que era defender la frontera o el valle, por lo que Sancho III lo donó al monasterio de San Martín de Albelda en cuyas manos no sabemos cuanto tiempo estuvo.

Cuando la Rioja fue incorporada a Castilla volvió a cobrar de nuevo el protagonismo inicial, al convertirse la Rioja en zona fronteriza con Navarra y Aragón. Las continuas disputas territoriales entre Castilla y Navarra alcanzan en tiempos de Alfonso VIII de Castilla y Sancho VI el Sabio de Navarra su punto álgido. El rey navarro arovechando la minoría de edad del castellano ocupó parte de la Rioja que después perdió, como se desprende de la reclamación que hizo el navarro de varias fortalezas en 1177 .

A finales del siglo XIII, durante el agitado reinado de Sancho IV, hijo de Alfonso $\mathrm{X}$ el Sabio, que había arrebatado ilegalmente el trono a sus sobrinos los Infantes de la Cerda, el castillo había caido en manos de D. Juan Alfonso de Haro, pero fue ganado para la corona por el Concejo de Logroño que lo recibió en premio.

En los últimos años del siglo XIV y durante todo el siglo XV los cambios de propiedad contínuos reflejan con extrema claridad la turbulenta época que vive la corona de Castilla.

Suponemos que Enrique II de Trastamara dió el castillo a alguno de sus partidarios en pago a sus servicios en la lucha por el trono contra su hermanastro Pedro I el Cruel, pues en 1396 pertenecia a D. Diego López de Zúñiga.

Después parece que revierte a la corona y en 1440 Juan II se lo concede a Juan de Luna, sobrino de su condestable, para volver otra vez a la familia López de Zúñiga que termina por venderlo a los condes de Aguilar, Señores de Cameros.

11 Govantes, C.: 1846 , p. 60.

12 Indice Colección Salazar y Castro.

13 Govantes, C.: 1846, p. 60. -Goicoechea, C.: Castillos de La Rioja. Notas descriptivas e históricas. Logroño, I.E.R. 1949 (Reprod. Logroño, Gobierno de la Rioja, Ayt. de Logroño, Caja Rioja y Asociación de Libros de La Rioja, 1987). Govantes, A. C.: Diccionario Geografico-historico de España. Sección II. Madrid, Imprenta de los Sres. Vda. de Jordán e hijos, 1846. 




Fig. 1 Planta del Castillo de Clavijo. 
EL CASTILlo DE CLAVIJO

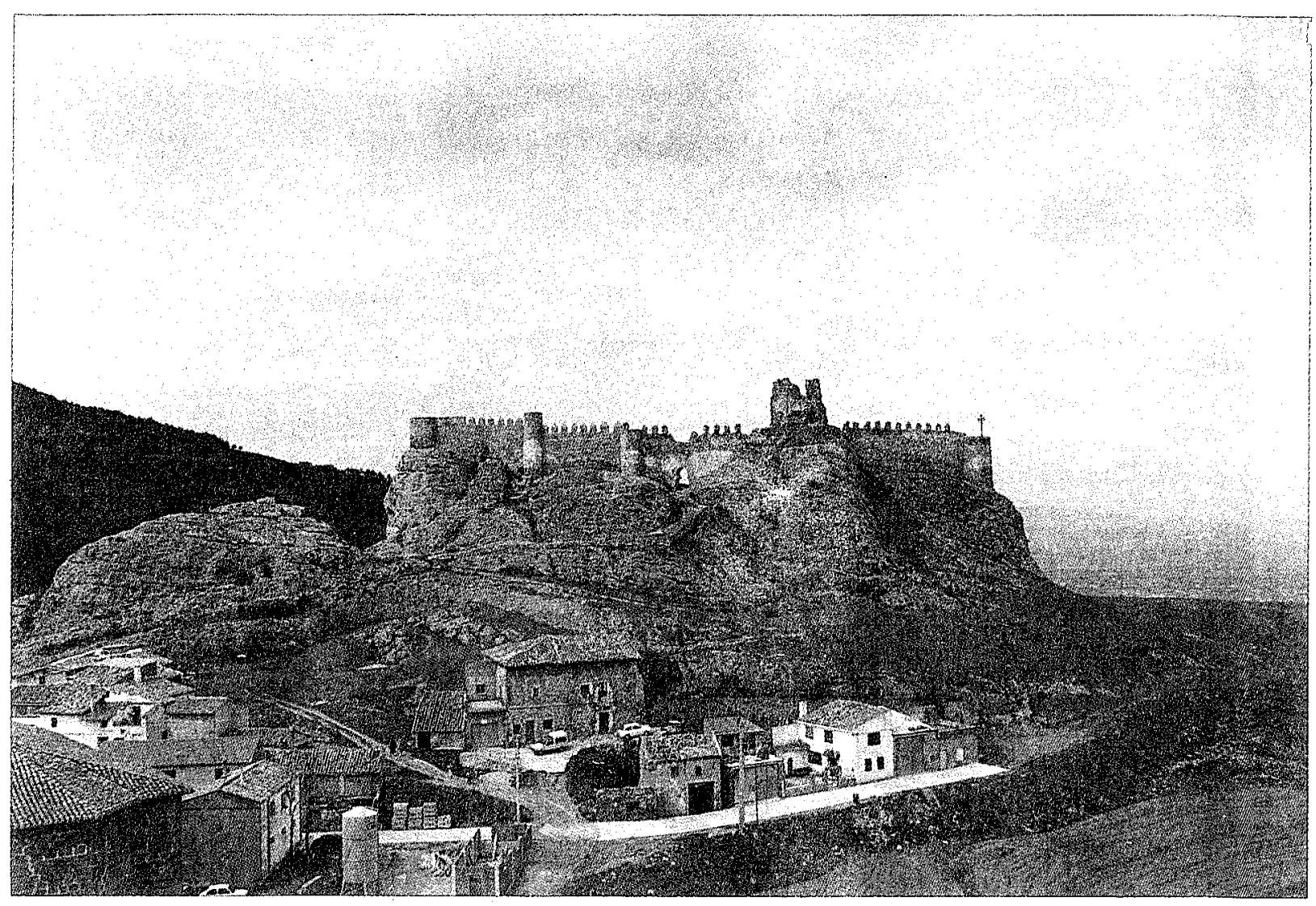

Lám. 1. Vista general del Castillo de Clavijo.

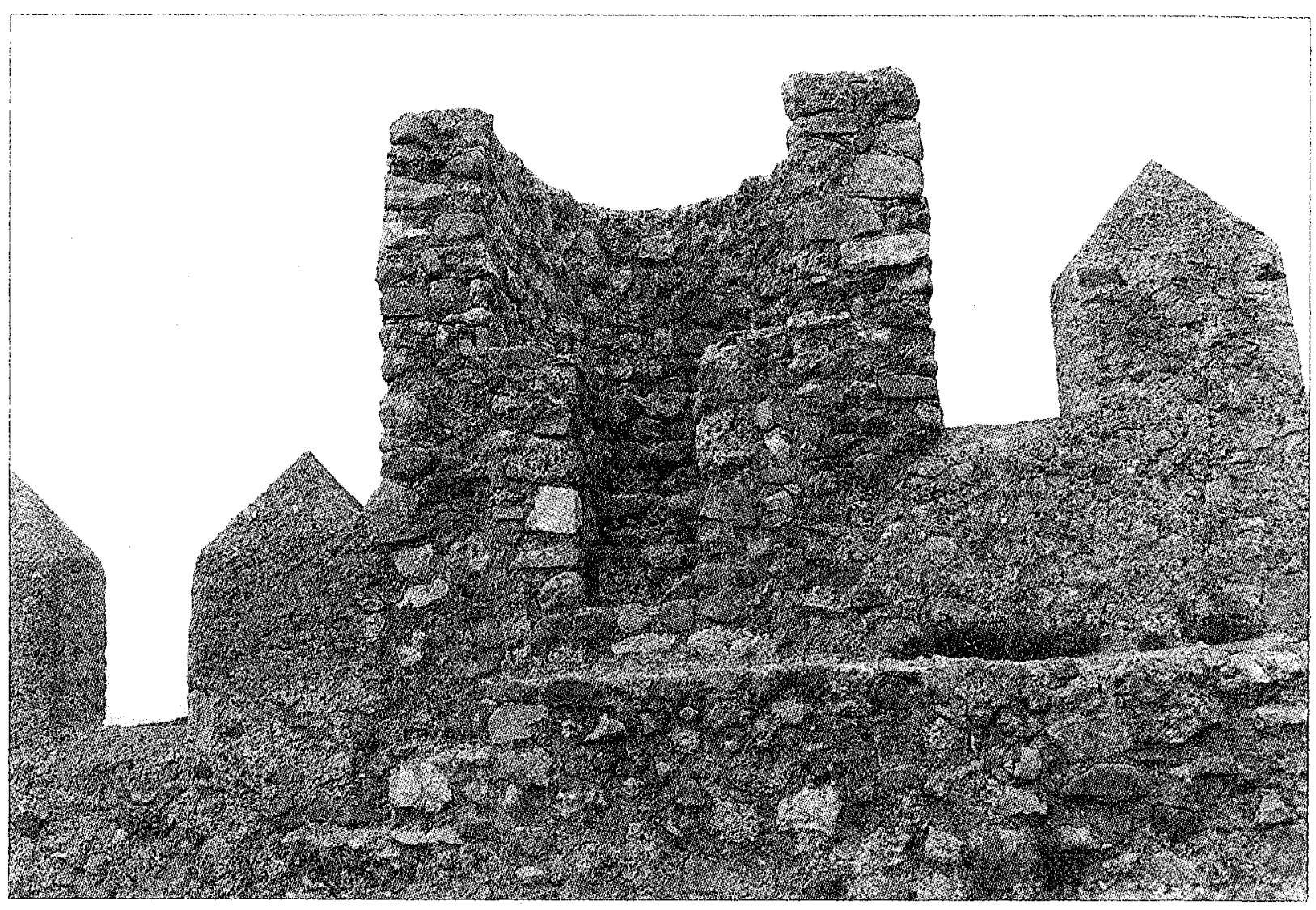

Lám. 2. Castillo de Clavijo. Muro y torreón norte. 




\section{EL CASTILlo DE CLAVIJO}

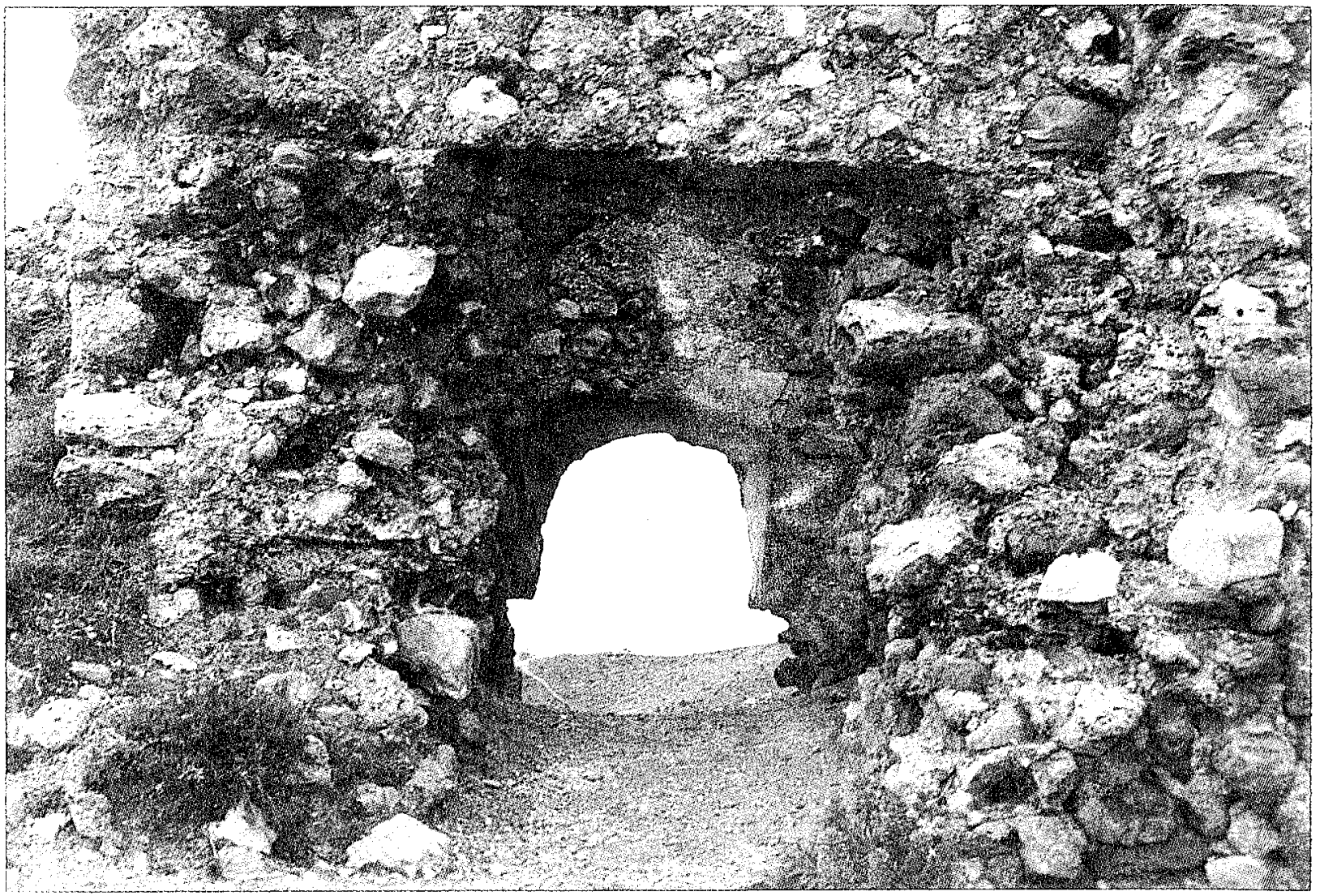

Lám. 5. Castillo de Clavijo. Cubo y muro occidental.



Lám. 6. Castillo de Clavijo. Vano desde el interior de la torre del homenaje. 

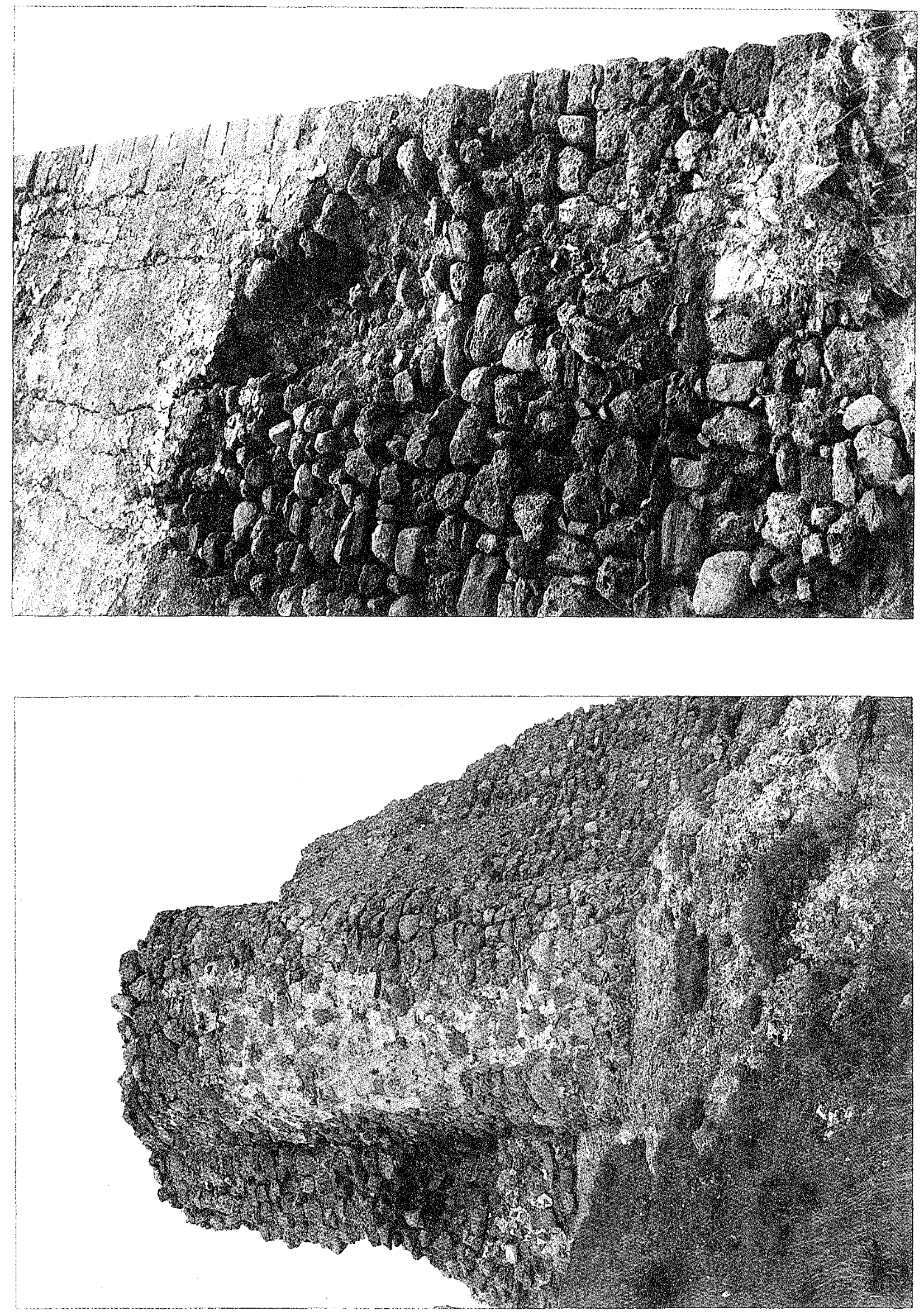